\title{
Perbedaan Kesuksesan Karir Subjektif Berdasarkan Tipe Orientasi Karir Pada Karyawan Middle Level Career Di Jakarta
}

\author{
Sari Zakiah Akmal, Fitri Arlinkasari, Intan Andryani \\ sari.zakiah@gmail.com
}

Fakultas Psikologi Universitas YARSI, Jakarta, Indonesia

\begin{abstract}
Karyawan akan melewati beberapa tahapan untuk mencapai kesuksesan karir. Karyawan pada tahap middle level career adalah mereka yang telah memiliki pengalaman dan diharapkan telah melakukan evaluasi terhadap pencapaian karirnya. Setelah melakukan evaluasi, karyawan akan lebih mengetahui sejauh mana kesuksesan karir yang telah dicapainya. Kesuksesan karir mengandung dua makna, yaitu kesuksesan karir secara objektif dan subjektif. Dalam perjalanan karir karyawan, orientasi karir merupakan indikator yang penting untuk mencapai kesuksesan karir. Terdapat lima tipe orientasi karir yang memiliki karakteristik berbeda yaitu, getting high, getting balanced, getting secure, getting free, dan getting ahead. Penelitian ini menggunakan metode kuantitatif untuk melihat perbedaan kesuksesan karir subjektif berdasarkan tipe orientasi karir pada karyawan middle level career. Subjek penelitian diperoleh dengan menggunakan incidental sampling terhadap sebanyak 205 orang karyawan middle level career yang bekerja di daerah Jakarta. Data penelitian diolah dengan menggunakan teknik statistik parametrik one way anova. Hasil penelitian menunjukkan bahwa terdapat perbedaan kesuksesan karir subjektif yang signifikan berdasarkan tipe orientasi karir $(\mathrm{F}=3.942 ; \mathrm{p}=0.004<0.05)$. Karyawan dengan tipe orientasi getting ahead memiliki kesuksesan karir subjektif yang lebih tinggi dibandingkan karyawan dengan tipe orientasi karir lainnya. Hasil penelitian ini dapat dimanfaatkan oleh perusahaan sebagai bahan pertimbangan dalam proses seleksi dan promosi karyawan yang sesuai dengan orientasi karirnya.
\end{abstract}

kata kunci: karyawan middle level career, orientasi karir, kesuksesan karir subjketif

Sebagai seorang karyawan, untuk mencapai kesuksesan karir harus melewati beberapa tahapan dalam karirnya. Salah satu tahap yang harus dilewati adalah tahap middle career. Pada tahap middle level career karyawan mengalami suatu transisi atau perubahan dalam karirnya meliputi pengalaman baru seperti penugasan khusus, promosi yang lebih tinggi, kesempatan untuk jenjang organisasi yang lebih tinggi, dan pembentukan nilai seseorang bagi organisasi atau perusahaan. Karyawan tersebut akan mengkaji ulang pencapaian selama karir dan memungkinkan mencapai karir pribadi serta tujuan hidup di masa depan (Simamora, 2004). Penelitian terdahulu mengenai kesuksesan karir pada karyawan middle level telah dilakukan oleh Kiruja dan Mukuru (2013) di Lembaga Pelatihan Publik Kenya. Hasil penelitiannya menunjukkan bahwa untuk mencapai kesuksesan karir, karyawan middle level menuntut pelayanan, upah, 
dan kondisi lingkungan kerja yang lebih baik. Selain itu, penelitian tersebut juga menemukan bahwa kinerja karyawan ditentukan oleh kegigihannya dalam bekerja. Beberapa karyawan middle level terlihat kurang gigih dalam bekerja karena tidak mendapat pengakuan dan pujian setelah melaksanakan tugas pekerjaan dengan baik.

Kesuksesan karir telah dikonseptualisasikan dan diukur secara objektif sebagai upah atau gaji, pangkat hingga promosi. Akan tetapi, adanya perubahan tentang sifat pekerjaan juga mengharuskan banyak perubahan pada karyawan untuk mencapai kesuksesan dan terdapat komponen subjektif dari kesuksesan karir (Shockley, dkk., 2015). Shockley, dkk. Juga menjelaskan bahwa terdapat delapan dimensi untuk mengukur kesuksesan karir subjektif karyawan. Delapan dimensi tersebut yaitu authenticity, growth and development, influence, meaningful work, personal life, quality work, recognition, dan satisfaction.

Terkait dengan komponen subjektif kesuksesan karir, hasil penelitian yang dilakukan oleh Ramadhani (2013) menunjukkan bahwa keseimbangan hidup akan mempengaruhi kesuksesan karir karyawan. Dalam hal ini karyawan merasa sukses tidak hanya menyangkut jumlah pendapatan atau tingginya gaji yang diterima. Melainkan ada aspek psikologis yang dibutuhkan oleh karyawan yaitu keseimbangan kehidupan pribadi dan pekerjaan. Pembagian waktu yang sama antara pekerjaan dan kehidupan pribadi adalah salah satu indikator kesuksesan karir karyawan. Karyawan tidak merasa terbebani oleh pekerjaan ataupun terhambat karena tumpukan beban kerja yang dapat mengurangi waktu mereka bersama keluarga dan teman-teman. Selain itu juga terdapat beberapa faktor yang dapat mempengaruhi kesuksesan karir karyawan seperti, jenis kelamin, usia, pendidikan, status perkawinan, minat, gaji, dan jabatan.

Perusahaan atau organisasi harus membantu pekerja memahami pengembangan aktivitas yang akan menuju pada kesuksesan karir. Agar sukses pada persaingan dalam lingkungan yang selalu berubah, maka perusahaan harus terus mengembangkan keterampilan pekerja yang ada sekarang sehingga tidak mudah tertinggal. Organisasi harus memberikan ruang gerak yang cukup bagi pekerja dalam mengembangkan kemampuan sehingga lebih produktif dan mempunyai komitmen yang lebih besar terhadap tujuan perusahaan. Tidak hanya itu, organisasi juga terus memiliki kepentingan dalam mengidentifikasikan faktor-faktor yang memprediksi kesuksesan karir untuk memilih secara efektif dan mengembangkan karyawan yang berpotensi tinggi (Sugiyanto, 2007).

Kesuksesan karir akan dicapai apabila karyawan mengetahui apa yang menjadi pandangan atau penilaian terhadap pekerjaannya. Konsep mengenai pandangan atau penilaian terhadap pekerjaan disebut sebagai orientasi karir. Menurut Derr (dalam Bridgstock, 2008) orientasi karir adalah sekumpulan motif, bakat, dan nilai-nilai yang membentuk standar dari waktu ke waktu sebagai hasil dari pengalaman kerja karyawan. Derr juga mengembangkan konsep orientasi karir menjadi lima tipe, yaitu getting high, getting balanced, getting secure, getting free, dan getting ahead. Lima tipe orientasi karir memiliki karakteristik yang berbeda. Karyawan dengan tipe getting high cenderung menyukai pekerjaan yang menarik, tantangan, dan kesempatan dalam pengembangan diri. Karyawan tipe getting 
balanced adalah mereka yang membutuhkan keseimbangan antara kehidupan pribadi dan pekerjaan. Karyawan tipe getting secure membutuhkan keamanan dalam pekerjaan dan cenderung memiliki solidaritas serta tertib dalam bekerja. Karyawan dengan tipe getting free adalah karyawan yang memerlukan otonomi dalam bekerja dan mencari kebebasan. Sedangkan karyawan dengan tipe getting ahead adalah mereka yang membutuhkan pengakuan dalam bekerja dan mencapai kemajuan melalui jajaran organisasi. Tipe orientasi karir yang dimiliki karyawan menjadi faktor yang menentukkan kesuksesan karir.

Oleh karena itu, penelitian ini bertujuan untuk mengetahui bagaimana perbedaan kesuksesan karir subjketif berdasarkan tipe orientasi karir pada karyawan middle level career. Peneliti berhipotesis bahwa tipe orientasi karir memiliki perbedaan kesuksesan karir subjektif yang dimiliki karyawan middle level career. Setiap karyawan memiliki orientasi karir dalam bekerja, namun dari kelima tipe orientsi karir ada satu tipe orientasi karir yang paling dominan dimiliki oleh karyawan tersebut. Dengan begitu, kesuksesan karir subjektif yang dimiliki seorang karyawan akan berbeda. Penelitian ini juga diharapkan dapat bermanfaat dalam segi ilmu pengetahuan bagi pembaca maupun praktisi-praktisi dalam dunia psikologi. Berdasarkan kajian tersebut bahwa hipotesis penelitian ini adalah terdapat perbedaan kesuksesan karir berdasarkan tipe orientasi karir pada karyawan middle level career.

\section{Metode}

Desain

Penelitian ini merupakan penelitian kuantitatif dengan jenis penelitian komparatif.

\section{Partisipan}

Partisipan penelitian ini adalah karyawan middle level career yang bekerja di DKI Jakarta. Sampel penelitian dalam penelitian ini berjumlah 205 orang karyawan middle level career. Sampel penelitian ini dipilih secara acak dengan menggunakan teknik non probilility, incidental sampling. Teknik ini digunakan karena peneliti tidak mengetahui secara pasti jumlah populasi dan sampel yang memenuhi kriteria cukup mudah ditemui dalam populasi.

\section{Instrumen Penelitian}

Skala Kesuksesan Karir Subjektif

Instrumen penelitian yang digunakan untuk mengukur kesuksesan karir subjektif pada penelitian ini adalah adaptasi skala Subjective Career Success Inventory (SCSI) yang disusun oleh Shockley, dkk. (2015). Skala ini terdiri atas 24 butir yang tersusun atas delapan dimensi, yaitu: authenticity, growth and development, influence, meaningful work, personal life, quality work, recognition, dan satisfaction.

Dalam melakukan adaptasi, peneliti melakukan uji coba pada skala kesuksesan karir subjektif. Hasil uji coba tersebut didapatkan nilai koefisien reliabilitas Cronbach's Alpha 0,897. Hal tersebut menunjukkan bahwa adaptasi pada skala ini reliabel. Sedangkan untuk validitasnya didapatkan nilai corrected item total 0,282-0,667 sehingga seluruh butir memenuhi kriteria butit yang baik. 
Skala Orientasi Karir

Instrumen penelitian yang digunakan untuk mengukur orientasi karir pada penelitian ini adalah modifikasi dari Career Orientation Assessment (COA) yang dibuat oleh Brooklyn Derr. Sebelum dilakukan modifikasi skala ini memiliki 29 pasang penyataan, namun peneliti melakukan modifikasi dengan menggunakan skala Likert sehingga jumlah butir menjadi 57 butir yang menggambarkan lima tipe orientasi karir, yaitu getting high, getting balanced, getting secure, getting free, dan getting ahead.

Dalam melakukan modifikasi, peneliti melakukan uji coba pada skala orientasi karir. Hasil uji coba didapatkan nilai Cronbach's Alpha pada getting high 0,742, getting balanced 0,809 , getting secure 0,842 , getting free 0,751 , dan getting ahead 0,680 yang menunjukkan bahwa modifikasi skala ini dapat dinilai reliabel. Sedangkan untuk validitasnya didapatkan nilai corrected item totaldengan rentang skor-0,036-0,714. Butir nomor 8, 10, 22, 31, 47, dan 51 dinyatakan gugur. Jumlah butir total skala orientasi karir menjadi 51 butir.

\section{Teknik Analisis Data}

Data dalam penelitian ini diolah dengan menggunakan beberapa uji analisis statistik, uji normalitas, dan uji one way anova untuk menguji hipotesis, serta uji beda untuk melihat keterkaitan faktor demografis dengan kedua variabel penelitian.

\section{Hasil}

\section{Uji Normalitas}

Uji normalitas pada penelitian ini dilakukan dengan menggunakan metode Kolmogorov-Smirnov. Data dikatakan normal apabila nilai signifikansi di atas alpha 0.05 (p> 0.05; Sunjoyo, 2012). Pengujian metode Kolmogorov-Smirnov menggunakan SPSS for Windows 16.0. Hasil uji normalitas secara keseluruhan memiliki nilai signifikansi 0,123 . Hasil ini menunjukkan bahwa data dalam penelitian ini berdistribusi normal.

\section{Uji One Way Anova}

Setelah dilakukan uji normalitas data, maka selanjutnya dilakukan uji hipotesis penelitian. Pengujian hipotesis penelitian menggunakan metode statistik parametrik karena hasil dari uji normalitas sebelumnya yang di dapatkan bahwa data berdistribusi normal. Teknik analisis yang digunakan adalah uji komparasi dilakukan dengan uji one way anova dengan menggunakan SPSS for Windows 16.0.

Tabel 1.

Hasil Uji Beda Kesuksesan Karir Subjektif

Berdasarkan Tipe Orientasi Karir.

\begin{tabular}{ccc}
\hline Variabel & F & Sig. \\
\hline Kesuksesan Karir & 3,942 & 0,004 \\
\hline
\end{tabular}

Berdasarkan hasil uji komparasi one way anova di atas, $\mathrm{F}=3,942(\mathrm{p}=0,004<$ 0,05) maka Ha diterima dan Ho ditolak yang artinya terdapat perbedaan kesuksesan karir subjektif yang signifikan berdasarkan tipe orientasi karir pada karyawan middle level career. Untuk mengetahui lebih lanjut perbedaan berdasarkan kelima tipe orientasi karir maka dilakukan uji komparasi menggunakan teknik posthoc. 
Tabel 2.

Hasil Posthoc Perbedaan Kesuksesan Karir Subjektif pada Masing-masing Tipe Orientasi Karir.

\begin{tabular}{|c|c|c|c|}
\hline $\begin{array}{c}\text { Tipe } \\
\text { Orientasi } \\
\text { Karir (I) }\end{array}$ & $\begin{array}{c}\text { Tipe } \\
\text { Orientasi } \\
\text { Karir }(\mathrm{J})\end{array}$ & $\begin{array}{c}\text { Mean } \\
\text { Difference } \\
(\mathrm{I}-\mathrm{J})\end{array}$ & Sig. \\
\hline \multirow[t]{4}{*}{ High } & Free & 3.36681 & .183 \\
\hline & Balance & -.91592 & .979 \\
\hline & Secure & -.90 & .981 \\
\hline & Ahead & -2.10526 & .639 \\
\hline \multirow[t]{3}{*}{ Balanced } & Free & $4.28273 *$ & $.037 *$ \\
\hline & Secure & .013 & 1.000 \\
\hline & Ahead & -1.18935 & .945 \\
\hline \multirow[t]{2}{*}{ Secure } & Free & $4.26897 *$ & $.043 *$ \\
\hline & Ahead & -1.230310 & .945 \\
\hline Ahead & Free & 5.47207 & $.004 *$ \\
\hline
\end{tabular}

Hasil uji posthoc didapatkan bahwa tipe orientasi karir getting ahead memiliki perbedaan kesuksesan karir subjektif yang signifikan dibandingkan tipe orientasi karir getting free dengan nilai $\mathrm{p}=0,004$. Tipe orientasi karir getting ahead memiliki kesuksesan karir subjektif yang lebih tinggi (mean=77,92) dibandingkan dengan tipe orientasi karir getting free (mean=72,44).

Tipe orientasi karir getting balanced memiliki perbedaan kesuksesan karir subjektif yang signifikan dibandingkan tipe orientasi karir getting free dengan nilai $\mathrm{p}=0,037$. Tipe orientasi karir getting balanced memiliki kesuksesan karir yang lebih tinggi (mean=76.73) dibandingkan dengan tipe orientasi karir getting free (mean=72,44). Selain itu, tipe orientasi karir getting secure $($ mean=76,71) memiliki perbedaan kesuksesan karir subjektif yang signifikan dibandingkan dengan tipe orientasi karir getting free (mean $=72,44)$ dengan nilai $\mathrm{p}=0,043$.

\section{Analisis Data Demografis}

Analisis tambahan terkait data penelitian dilakukan dengan membandingkan kesuksesan karir subjektif berdasarkan data demografis yang secara teoretis terkait dengan kesuksesan karir subjektif karyawan. Dari hasil uji beda berdasarkan variabel kesuksesan karir subjektif, terdapat perbedaan kesuksesan karir subjektif yang signifikan berdasarkan tingkat pendidikan ( $\mathrm{F}=8,314, \mathrm{p}=0,000<$ 0,05) dan gaji $(\mathrm{F}=9,132 \mathrm{p}=0,000<0,05)$ karyawan dengan tingkat pendidikan S-1 memiliki kesuksesan karir subjektif yang lebih tinggi dibandingkan karyawan tingkat pendidikan SMA dengan nilai $\mathrm{p}=0,000<0,05$. Selain itu, karyawan dengan tingkat pendidikan S-2 juga memiliki kesuksesan karir subjektif yang lebih tinggi dibandingkan dengan karyawan tingkat pendidikan SMA atau SMK dengan nilai $\mathrm{p}=0,001<0,05$. Selain itu, karyawan yang memperoleh gaji 4,5 juta - 6 juta memiliki kesuksesan karir subjektif yang lebih tinggi dibandingkan karyawan yang memperoleh gaji kurang dari 2,5 juta. Karyawan yang memperoleh gaji di atas 6 juta memiliki kesuksesan karir subjektif yang lebih tinggi dibandingkan karyawan yang memperoleh gaji di bawah 6 juta.

\section{Diskusi}

Berdasarkan hasil analisis penelitian di atas, dapat diketahui bahwa terdapat perbedaan yang signifikan antara kesuksesan karir subjektif berdasarkan tipe orientasi karir. Hal tersebut tergambar pada hasil uji one way anova dengan nilai $\mathrm{F}=4,432$ dan nilai $\mathrm{p}=0,02<0,05$. Perbedaan kesuksesan karir subjektif berdasarkan tipe orientasi karir diperkirakan dapat terjadi karena setiap tipe orientasi karir memiliki karakteristik yang berbeda jika dikaitkan dengan dimensi-dimensi kesuksesan karir subjektif. Karyawan tipe orientasi getting 
ahead (mean=77,92) memiliki kesuksesan karir yang paling tinggi dan karyawan tipe orientasi getting free (mean=72,44) memiliki kesuksesan karir paling rendah di antara tipe orientasi karir lainnya.

Hasil analisis data penelitian menunjukkan bahwa karyawan middle level career dengan tipe orientasi karir getting ahead memiliki kesuksesan karir yang lebih tinggi dari karyawan middle level career dengan tipe orientasi getting free. Mayoritas karyawan tipe orientasi karir getting ahead memiliki kesuksesan karir sedang berjumlah 15 orang (42\%), sedangkan karyawan tipe orientasi karir getting free memiliki kesuksesan karir rendah berjumlah 24 orang (49\%). Hasil penelitian ini berbeda dengan penelitian yang dilakukan oleh Bridgstock (2008) tentang tipe orientasi pada pekerja industri kreatif di Australia, di mana pekerja atau karyawan yang memiliki tipe orientasi karir getting free memiliki pendapatan yang relatif tinggi dan dinilai memiliki keberhasilan diri yang tinggi pula.

Pada penelitian ini karyawan dengan tipe orientasi karir getting free mendapatkan nilai terendah. Hal tersebut dikarenakan karyawan getting free memerlukan ruang yang luas dan bebas untuk pekerjaannya, mereka tidak bisa terikat pada suatu norma atau aturan. Karyawan getting free hanya bekerja untuk mencapai kontrol maksimum atas pekerjaannya dan terkadang memutuskan untuk keluar dari batasan yang ada. Hal tersebut berbeda dengan karyawan getting ahead yang memandang karir sebagai salah satu cara untuk mencapai kemajuan dalam sebuah hirarki agar mendapat pengakuan. Dalam penelitian ini, kesuksesan karir yang dimiliki oleh karyawan dengan tipe orientasi getting ahead diperkirakan berkaitan dengan dimensi kesuksesan karir subjektif growth and development, di mana karyawan akan mengembangkan karir melalui pengembangan pengetahuan dan keterampilan. Selain itu, hal ini juga diperkirakan berkaitan dengan dimensi authenticity dan influence sehingga dapat mengarahkan karir sesuai dengan kebutuhan pribadi dan pengaruh pada orang lain dalam organisasi.

Karyawan dengan tipe orientasi karir getting balanced memiliki kesuksesan karir subjektif yang lebih tinggi dibandingkan karyawan getting free. Mayoritas karyawan dengan tipe orientasi karir getting balanced memiliki kesuksesan karir rendah dan sedang sama yaitu berjumlah 12 orang (29\%). Hal ini juga berbeda dengan hasil penelitian sebelumnya yang dilakukan Bridgstock (2008), di mana karyawan tipe getting free memiliki pendapatan yang relatif tinggi dan juga dinilai memiliki keberhasilan diri. Sedangkan karyawan tipe getting balanced mendapatkan nilai yang seimbang antara pendapatan dan keberhasilan diri.

Dalam penelitian ini karyawan dengan tipe getting balanced memiliki kesuksesan karir subjekif yang lebih tinggi dibandingkan karyawan getting free. Hal tersebut dapat diketahui dari karakteristik karyawan berdasarkan tipe orientasi karir. Karyawan getting balanced mencoba menghadirkan keseimbangan antara kehidupan pribadi dan pekerjaan. Selain itu, hal ini diperkirakan berkaitan dengan adanya dimensi personal life dalam kesuksesan karir subjektif yang mendorong karyawan getting balanced untuk lebih meiliki karir yang berdampak positif di luar kehidupan pekerjaannya. Hal ini berbeda dengan karyawan getting free yang bekerja hanya untuk mencapai kontrol maksimum atas pekerjaannya. 
Selanjutnya, karyawan dengan tipe orientasi karir getting secure juga memiliki kesuksesan karir subjektif yang lebih tinggi dibandingkan karyawan dengan tipe orientasi karir getting free. Mayoritas karyawan dengan tipe orientasi karir getting secure memiliki kesuksesan karir sedang berjumlah 16 orang (41\%). Hal ini sangat berbeda dengan hasil penelitian Bridgstock (2008) di mana karyawan dengan tipe orientasi getting secure memiliki pendapatan dan keberhasilan diri yang rendah pula. Karyawan getting secure bertujuan untuk mencapai keamanan kerja, kondisi yang stabil dan terhormat, serta pengakuan.

Karyawan getting secure yang sukses dapat dilihat dari konteks pekerjaan bukan kontennya. Hal ini diperkirakan berkaitan dengan dimensi recognition pada kesuksesan karir subjektif di mana mereka akan merasa dihargai orang lain baik secara formal maupun informal. Tipe orientasi ini mencari promosi yang tepat untuk kemajuan karir. Sementara itu, karyawan dengan tipe getting free akan menghilangkan kewajiban dalam bekerja dan tidak ingin terikat dalam suatu norma atau aturan. Karyawan yang merasa dihargai dalam pekerjaannya akan lebih sukses dalam karir.

Hasil penelitian tambahan mengaitkan kesuksesan karir subjektif dengan data tambahan yang terkait dengan kesuksesan karir karyawan. Jika ditinjau dari variabel kesuksesan karir subjektif, tingkat pendidikan dan gaji yang diperoleh mempunyai hasil yang signifikan. Karyawan middle level career dengan tingkat pendidikan S-1 dan S-2 memiliki kesuksesan karir subjektif yang lebih tinggi dibandingkan karyawan dengan tingkat pendidikan SMA atau SMK. Hal ini juga sejalan dengan hasil penelitian
Nabi (dalam Rambe, 2005) bahwa karyawan yang sukses berkarir secara subjektif adalah mereka yang berpendidikan tinggi. Artinya, karyawan middle level career dengan tingkat pendidikan tinggi seperti S-1 atau S-2 akan lebih merasa sukses karirnya daripada karyawan middle level career yang memiliki tingkat pendidikan SMA atau SMK.

Besarnya jumlah gaji yang diperoleh juga mempunyai hasil yang signifikan dengan variabel kesuksesan karir subjektif. Hasil uji beda data demografis gaji didapatkan bahwa karyawan yang memperoleh gaji 4,5 juta - 6 juta memiliki kesuksesan karir subjektif yang lebih tinggi dibandingkan karyawan yang memperoleh gaji < 2,5 juta. Tidak hanya itu, karyawan yang memperoleh gaji $>6$ juta memiliki kesuksesan karir subjektif yang lebih tinggi dibandingkan karyawan yang memperoleh gaji di bawah 6 juta. Noe (dalam Sugiyanto, 2007) menjelaskan bahwa tujuan karir seseorang berhubungan dengan outcome yang ingin dicapai salah satunya adalah gaji. Hal tersebut didukung oleh hasil penelitian yang dilakukan oleh Rambe (2005) bahwa semakin tinggi gaji karyawan, maka mereka akan merasa puas pada karir yang dicapainya. Perasaan puas yang dimiliki karyawan merupakan salah satu dimensi dari kesuksesan karir subjektif (satisfaction).

Peneliti menyadari masih terdapat kekurangan dan keterbatasan pada penelitian ini sehingga dapat dijadikan sebagai masukan (saran) untuk penelitian berikutnya. Kekurangannya berada pada sampel peneliian yang berjumlah 205 karyawan middle level career di Jakarta.

Hal tersebut dikhawatirkan belum mewakili karyawan middle level career yang bekerja di Jakarta. Oleh karena itu, 
penelitian berikutnya disarankan untuk memperbesar jumlah sampel agar lebih dapat mewakiliki populasi karyawan di Jakarta.

Penelitian ini dilakukan di seluruh bidang pekerjaan, tidak spesifik pada bidang pekerjaan tertentu. Peneliti berasumsi bahwa bidang pekerjaan dapat menjadi faktor yang menyebabkan perbedaan tipe orientasi karir karyawan. Akan tetapi, pada penelitian ini peneliti tidak mencantumkan bidang pekerjaan di data kontrol. Akibatnya, penelitian ini tidak dapat menganalisis lebih dalam mengenai tipe orientasi karir dan kesuksesan karir subjektif pada bidang pekerjaan tertentu. Oleh karena itu, penelitian berikutnya sebaiknya mencantumkan bidang pekerjaan yang lebih detil sehingga dapat dilakukan analisis orientasi karir yang spesifik pada bidang pekerjaan tertentu.

Selain saran teoretis/metodologis, penelitian ini juga dapat memberikan saran praktis, yaitu:

1. Hasil penelitian ini dapat dijadikan sebagai landasan dalam proses rekrutmen karyawan dan promosi jabatan. Dengan mengetahui tipe orientasi karyawan diharapkan perusahaan atau instansi akan lebih mudah dalam proses penempatan karyawan. Karyawan dengan tipe orientasi karir getting ahead lebih cocok dipromosikan untuk jabatan yang lebih tinggi, sedangkan karyawan dengan tipe orientasi karir getting free membutuhkan pekerjaan yang memiliki ruang serta fleksibilitas dalam bekerja.

2. Bagi karyawan dapat mengenali tipe orientasi karir yang dimiliki untuk lebih sukses secara subjektif dalam karirnya. Karyawan yang telah mengetahui tipe orientasi karir dapat mencari cara yang paling sesuai dengan tipe orientasi karirnya untuk mencapai kesuksesan karir.

\section{Kesimpulan}

Hasil analisis menunjukkan bahwa karyawan dengan tipe orientasi karir getting ahead memiliki kesuksesan karir subjektif yang lebih tinggi dibandingkan dengan tipe orientasi karir getting free. Tipe orientasi karir getting ahead memiliki kesuksesan karir subjektif yang lebih tinggi dibandingkan getting free. Tipe getting balanced memiliki kesuksesan karir subjektif yang lebih tinggi dibandingkan getting free. Selain itu, tipe getting secure juga memiliki kesuksesan karir subjketif yang lebih tinggi dibandingkan dengan getting free. Dengan kata lain, karyawan dengan tipe orientasi karir getting free memiliki kesuksesan karir subjektif yang paling rendah dicantara tipe orientasi karir lainnya pada sampel penelitian ini. Hasil penelitian ini dapat dimanfaatkan oleh perusahaan maupun karyawan. Bagi perusahaan, dengan mengetahui orientasi karir karyawan dapat dijadikan bahan pertimbangan dalam proses rekrutmen dan promosi jabatan karyawan. Sedangkan bagi karyawan, dengan mengetahui tipe orientasi karir yang dimiliki dapat mencari cara yang paling sesuai dengan tipe orientasi karirnya untuk mencapai kesuksesan karir.

\section{Daftar Pustaka}

Bridgstock, R. (2008). Follow your bliss' or 'show me the money? Career orientations, career management competence, and career success in Australian creative workers. Norwich Business School: University of East Anglia. 
Simamora, Henry. (2004). Manajemen Sumber Daya Manusia Edisi Ketiga. Yogyakarta: STIE YKPN.

Kiruja, E. K. \& Elegwa, M. (2013). Effect of motivation on employee performance in public middle level technical training institutions in Kenya. International Jorunal of Advances in Management and Economics, 2(4), 73-82.

Ramadhani, M. (2013). Analisis Pengaruh Keseimbangan Kehidupan-Kerja Terhadap kesuksesan karir. Jurnal Ilmiah Mahasiswa FEB Universitas Brawijaya, 1(2).

Rambe, R. A. (2005). Apakah demografi dan mentor masih penting dalam menentukan kesuksesan karir pegawai. Jurnal Siasat Bisnis, 1(10).

Shokley, K., Heather, U., Ozgun, B., Laura F., \& Timothy, R. (2015). Development of a new scale to measure subjective career success: A mixed-methods study. Journal of Organizational Behavior.

Sugiyanto. (2007). Pengaruh human capital, motivasi dan dukungan atasan terhadap kesuksesan karir karyawan: studi empiris di PT. Asian Cotton Bandung. Jurnal Akuntansi Manajemen Bisnis.

Sugiyono. (2010). Statistika untuk Penelitian. Bandung: Alfabeta.

Sunjoyo. (2013). Aplikasi SPSS untuk Smart Riset. Bandung: Alfabeta. 